\title{
Çok Düşük Doğum Ağırlıklı Preterm Bebeklerde Retinol Metabolizması Değişkenlerinin Prematüre Retinopatisi ile İlişkisi
}

\author{
The Relationship of Retinol Metabolism Variables with Retinopathy of Prematurity in \\ Preterm Babies with Very Low Birth Weight
}

\author{
Kadir Şerafettin Tekgündüz ${ }^{1}$, Dilara Dilek ${ }^{2}$, Mustafa Kara ${ }^{3}$, Mustafa Yıldırım ${ }^{4}$, \\ Sibel Ejder Tekgündü̈ ${ }^{5}$ \\ ${ }^{1}$ Atatürk Üniversitesi Tip Fakültesi, Çocuk Sağhlğı ve Hastalıkları Anabilim Dalı, Neonatoloji Bilim Dalı, Erzurum. \\ ${ }^{2}$ Atatürk Üniversitesi Tip Fakültesi, Çocuk Sağhl̆̆ ve Hastalıkları Anabilim Dalı, Erzurum. \\ ${ }^{3}$ Atatürk Üniversitesi Tip Fakültesi, Çocuk Sağlığı ve Hastalıkları Anabilim Dalı, Neonatoloji Bilim Dalı, Erzurum. \\ ${ }^{4}$ Atatürk Üniversitesi Tip Fakültesi, Göz Hastalıkları Anabilim Dalı, Erzurum. \\ ${ }^{5}$ Sağlık Bakanlı̆̆ı Erzurum Bölge Eğitim ve Araştırma Hastanesi, Kadın Hastalıkları ve Doğum Kliniği, Erzurum.
}

\author{
Yazışma Adresi / Correspondence: \\ Kadir Şerafettin Tekgündüz \\ Atatürk Üniversitesi Tıp Fakültesi, Çocuk Sağlığı ve Hastalıkları Anabilim Dalı, Neonatoloji Bilim Dalı, Erzurum, Türkiye \\ T: $+904423447696 \quad$ E-mail : k.tekgunduz@yahoo.com.tr \\ Geliș Tarihi / Received : 13.04.2021 Kabul Tarihi / Accepte: 09.09.2021 \\ Orcid : \\ Kadir Şerafettin Tekgündüz https://orcid.org/0000-0001-6375-5644 \\ Dilara Dilek https://orcid.org/0000-0001-6375-5644 \\ Mustafa Kara https://orcid.org/0000-0001-6568-1538 \\ Mustafa Ylldırım https://orcid.org/0000-0002-2706-3592 \\ Sibel Ejder Tekgündüz https://orcid.org/0000-0002-0992-1944 \\ (Sakarya Tip Dergisi / Sakarya Med J 2021, 11(3):654-660 ) DOI: 10.31832/smj.915100
}

\footnotetext{
$\ddot{0} z$

Amaç Retinol fetusta birçok organın gelișimi için gereklidir. Bu nedenle retinol eksikliği teratojenik etkilere neden olabilir. Bu çalıșmada çok düșük doğum ağırlıklı bebeklerde retinol, retinol bağlayıcı protein (RBP) ve plasental retinol transfer hızı düzeyleri ile prematüre retinopatisi (ROP) arasındaki ilişkiyi araștırmayı amaçladık.

Gereç ve Calıșma Ocak-Aralık 2020 tarihleri arasında prospektif kohort olarak yürütüldü. Calıșmaya $\leq 30$ hafta ve $\leq 1500$ gr doğan bebekler dahil edildi. Major anomalileri olan Yöntemler anne ve bebekler dahil edilmedi. Retinol ve RBP seviyeleri umblikal kord ve anne kanında çalışıldı. Plasental retinol transfer oranını hesaplandı. Retinol, RBP ve plasental transfer oranının karşılaștırması herhangi bir evre ROP (+) ve ROP (-) grupları arasında yapıldı. ROP tedavisi gerektiren hastalarda retinol, RBP durumu ve plasenta transfer oranının etkileri araștırıldı.

Bulgular Toplam 30 hastanın ROP incelemeleri tamamlandı. ROP olan ve olmayanların umblikal kord ve maternal retinol seviyeleri arasında istatistiksel olarak anlamlı bir fark görülmezken, plasental retinol transfer hızı ROP (+) grubunda anlamlı olarak daha düşüktü. Plasental retinol transfer hızı ile ROP evresi arasında negatif korelasyon vardı. ROP olanların alt grup analizinde, tedaviye ihtiyaç duyanların plasental retinol transfer oranının ROP olmayanlara göre daha düşük olduğu bulundu.

Sonuç Plasental retinol transfer hızı, prematüre bebeklerde tedavi gerektiren ROP için bir prediktif faktör olarak kullanılabilir. Ancak daha geniş katılımlı çalısmalara ihtiyaç vardır

Anahtar preterm bebek; prematüre retinopatisi; retinol

Kelimeler

Abstract

Objective Retinol is essential for the development of many organs in the fetus. Therefore, retinol deficiency can cause teratogenic effects. We aimed to investigate the relationship between retinol, retinol binding protein $(R B P)$ and placental retinol transfer rate levels and retinopathy of prematurity (ROP) in very low birth weight infants.

Materials The study was conducted as a prospective cohort from January to December 2020. Preterm infants who born at $\leq 30$ weeks and $\leq 1500 \mathrm{gr}$ were included in the study. Mothers and infants and Methods with major anomalies were not included. Retinol and RBP levels were measured from umblical cord blood and mothers. The placental retinol transfer rate was calculated. The comparison of retinol, RBP and placental transfer rate was made between any stage $R O P(+)$ and $R O P(-)$ groups. The effects of retinol, RBP status and placental transfer rate in patients requiring ROP treatment were investigated.

Resulrs The ROP examinations of a total of 30 patients have been completed. No statistically significant difference was noted between the umblical cord and maternal retinol levels of those with or without the development of ROP. In contrast, placental retinol transfer rate was significantly lower in $R O P(+)$ group. There was a negative correlation between placental retinol transfer rate and ROP stage. In the subgroup analysis of those with ROP, the placental retinol transfer rate of those who needed treatment was lower than those without ROP.

Conclusion Placental retinol transfer rate can be used as a predictive factor for ROP requiring treatment in preterm infants. However, studies with larger participation are needed.

Keywords preterm infants; retinopathy of prematurity; retinol
} 


\section{GIIRIŞ}

Prematüre retinopatisi (ROP) gelişmekte olan retinanın vazoproliferatif bir hastalığıdır. Başlıca risk faktörleri olarak prematürite, düşük doğum ağırlığı, postnatal oksijen tedavisi süresi sayılabilir., ${ }^{1,2}$ Doğum ağırlığı ve gestasyon yaşı düştükçe tedavi gerektiren ROP görülme sıklığı artmaktadır. ${ }^{1}$ Antenatal oksidan maruziyetinin de ROP gelişimi üzerine etkili olduğu bildirilmiştir. ${ }^{3}$ Bu durum aslında antenatal dönemden itibaren retina gelişimi üzerine etkili faktörlerin rolü olduğunu göstermektedir. Ancak halihazırda hangi bebekte tedavi gerektiren ROP gelişeceğini doğum sırasında öngörmek mümkün değildir. Amerikan Pediatri Akademisi ve Amerikan Oftalmoloji Akademisi doğum ağırlı̆̆ $\leq 1500 \mathrm{~g}$ ve/veya gestasyon haftası $\leq 30 \mathrm{hf}$ olan bebeklerde ve 30 hafta üzerinde 1500-2000 g doğup kardiyopulmoner destek ihtiyacı olmuş pretermlerde ROP açısından takip yapılmasını önermektedir. ${ }^{4}$

Retinol (vitamin A) fetus için esansiyel bir vitamindir ve anne tek retinol kaynağıdır. Embriyonik retinol eksikliğinin konjenital anoftalmi ve mikroftalmiyi içeren multiorgan anomalilerine neden olabildiği bilinmektedir., Bunun yanında antenatal retinol fazlalığının da teratojenik etkileri vardır. ${ }^{7}$ Dolayısıyla fetusa retinol sunumunun dengelenmesinde plasental homeostazın önemli rolü bulunmaktadir. ${ }^{8-9}$

Biz çalışmamızda çok düşük doğum ağırlıklı (ÇDDA) prematüre bebeklerde umblikal kord, anne retinol, retinol bağlayıcı protein (RBP) seviyeleri ve plasental retinol geçiş hızı ile ROP arasındaki ilişkiyi incelemeyi hedefledik.

\section{GEREÇ ve YÖNTEMLER}

Çalışma, Ocak - Aralık 2020 tarihleri arasında prospektif kohort olarak Atatürk Üniversitesi Tip Fakültesi Yenidoğan Yoğun Bakım Ünitesinde yürütüldü. Çalışma için hasta alımı Ekim 2020 tarihinde tamamlandı, ROP muayene takipleri devam etti. Çalışma için Atatürk Üniversitesi Tip Fakültesi Etik Kurulu'ndan onay alındı (Onay no: 20207/29). Tüm hastaların ailelerine "Bilgilendirilmiş Onam
Formu" verildi ve yazılı onamları alındı. Çalışmada Helsinki Bildirgesi kurallarına uyuldu.

\section{Çalışma planı}

Hastanemizde doğan $\leq 30$ hafta ve $\leq 1500$ gr prematüre bebekler ve anneleri çalışmaya dahil edildi. Anne veya bebekte doğuştan metabolik hastalık, konjenital major anomali olması, annede kronik karaciğer, böbrek ve gastrointestinal sistem hastalığı olması, çalışma dışı bırakılma kriterleri idi. Aileden onam alınıp serum örnekleri toplanmış olanlardan ROP muayenesi tamamlanmadan exitus olan bebekler çalışmadan çıkarıldı.

Çalışmaya alınan bebeklerin demografik verileri, anne yaşı, annenin gebeliğinin primipar olup olmadığı, preeklampsi/eklampsi, gestasyonel diyabet ve antenatal steroid yapılma durumu kaydedildi. Gebelikte vitamin kullanma durumu ve süresi sorguland.

İlk ROP muayenesi Türk Neonatoloji ve Türk Oftalmoloji derneklerinin hazırladığ 1 rehber doğrultusunda yapıldı. ${ }^{10}$ Gestasyon yaşı 28 haftanın altında doğmuş bebeklerde postmenstruel 31. haftada, 25 hafta altında doğanlarda postnatal 6. haftada, 28 hafta üzerinde doğanlarda ise postnatal 4. haftada ROP muayene tarama programı başlatılıp göz hekiminin uygun gördüğü aralıklarla takip devam etti. Tedavilere rehber doğrultusunda karar verildi. ${ }^{10}$ Endikasyona göre lazer ablasyon veya vasküler endotelyal büyüme faktör blokajı (anti-VEGF) yapıldı.

\section{Örneklerin alınması ve çalışması}

Çalışmaya alınan tüm bebekler için doğumda umblikal korddan deneyimli kişiler tarafından vacutainer kullanılarak, doğumdan hemen sonra annelerinden antekübital bölgeden yaklaşık $6 \mathrm{ml}$ venöz kan biyokimya tüpüne alındı ve pıhtılaşmaları tamamlandıktan sonra 4500 RPM'de, 10 dakika satrifüj edilerek serumları ayrıldı. Serum örnekleri $-80^{\circ}$ derecede dondurularak analiz edilinceye kadar saklandı. Analiz işlemleri için serum örnekleri uygun koşullarda çözülmeleri sağlandıktan sonra tüm analizler tek 
oturumda Atatürk Üniversitesi Tıbbi Biyokimya Laboratuvarında yapıldı.

Serum örneklerinde retinol düzeyi Bioassay Technology Laboratory (E1548Hu Jiaxing, Zhejiang, China ) ELİSA kitleri ve RBP düzeyi Elabscience ( E-EL-H1581 Texas USA) ELİSA kitleri ile üreticinin önerdiği standart protokole uygun olarak Dynex otomatik ELİSA okuyucu cihazında (Dynex Technologies Headquarters, Chantilly, USA) analiz edildi. Retinol için kitin ölçüm aralığı 2ng/ml- 800 ng/ml, RBP için kitin ölçüm aralığı 0,07 - 100 ng/mL idi. Plasental retinol geçiş hızı annedeki retinolün yüzde kaçının umblikal korda geçebildiğini göstermesi için umblikal kord retinol/maternal retinol x 100 formülü ile hesapland1. ${ }^{11}$

\section{İstatistiksel Analiz}

İstatistik analiz SPSS 23 programı (SPSS, Chicago, Illinois, USA) kullanılarak yapıldı. Katerogorik verilerin dağılım sıklığı (sayı ve yüzde), sayısal verilerin özellikleri (median, minimum, maksimum) için tanımlayıcı istatistikler yapıldı. Normallik dağılımını analiz etmek için Shapiro-Wilk ve Kolmogorow-Smirnov testleri kullanıldı. Çalışma grubunda değerlerin non-parametrik dağıldığı belirlendi. Süreklilik gösteren verilerin etkisinin değerlendirilmesinde Mann-Whitney U ve Kruskall Wallis testleri kullanıldı. ROP olmayan, ROP (+) tedavi yok ve ROP (+) tedavi var gruplarının süreklilik gösteren verilerinin karşılaştırılmasında Kruskall Wallis testi kullanıldı. Post-hoc analiz için ikili grupların karşılaştırması Bonferroni düzeltmeli Mann Whitney U testi ile yapıldı. Kategorik verilerin karşılaştırılmasında ki-kare testi kullanıldı. Spierman's korelasyon testi ile süreklilik gösteren değişkenlerin korelasyonunun olup olmadığı analiz edildi. P değerinin $<0,05$ olması anlamlı olarak kabul edildi.

\section{BULGULAR}

Hasta alımı periyodunda $\leq 30$ hafta ve $\leq 1500$ gr toplam 67 bebek doğdu, çalışma kriterlerini karşılayan ve aile onamı alınabilen 41 preterm çalışmaya dahil edildi. Ancak bu be- beklerden 30 tanesinin ROP muayenesi tamamlanabildi.

Toplam 30 bebekten 17 'si $(\% 56,6)$ erkek, 13’ü $(\% 43,4)$ k1z idi. Bebeklerin doğum haftası ortanca 29 (25-30) hafta, doğum ağırlığı ortanca 1080 gr (570-1490), anne yaşı ortanca 27,5 (17-41) idi. Gebeliklerin 7’si (\%23,3) primipar, 23 'ü $(\% 67,7)$ multipar idi. Annelerden 3’ü (\%10) gebelik süresince 30-90 gün arasında vitamin kullanmıştı. Ek A vitamin alan anne yoktu. Annelerin 8'inde $(\% 26,6)$ preeklampsi vardı. Hiçbir annede diabetes mellitus yoktu. Antenatal steroid $22(\% 73,3)$ anneye uygulanmıştı.

Tüm hastaların umblikal kord retinol ve RBP düzeyleri sirasiyla ortanca 199,8 ng/ml (147,5-663,8), 7,96 ng/ml (0,71-37,83); annelerin retinol ve RBP düzeyleri sirasiyla ortanca $170,7 \mathrm{ng} / \mathrm{ml}(123,3-496,1), 0,87 \mathrm{ng} / \mathrm{ml}(0,16-$ $24,87)$ idi. Hastaların umblikal kord retinol anne retinol düzeylerinden; umblikal kord RBP anne RBP düzeylerinden istatistiksel olarak anlamlı şekilde yüksekti ( $\mathrm{p}<0,001$, $\mathrm{p}<0,001)$. Bununla birlikte anne retinol ile umblikal kord retinol düzeyleri arasında pozitif korelasyon ( $r: 0,45$, p:0,013) var iken, anne RBP ile umblikal kord RBP düzeyleri arasinda korelasyon saptanmadi (r:0,06, p:0,973) Plasental retinol geçiş hızı ortanca \%120 (62-189) idi. Antenatal steroid uygulananlar ile uygulanmayanlar arasinda umblikal kord ve anne retinol, RBP düzeyleri ve plasental retinol geçiş hızı açısından istatiksel anlamlı fark yoktu (sirasiyla p:0,362, p:0,980, p:0,271, p:0,941, p:0,683). Hastaların demografik verileri, anne yaşı, primipar olma, preeklampsi, vitamin kullanımı ile umblikal kord ve anne retinol, RBP, plasental retinol transfer hızı arasında ilişki saptanmadi.

Bebeklerin 13'ünde $(\% 43,4)$ herhangi bir evre ROP saptanırken $17(\% 56,6)$ hastada ROP yoktu. ROP olan hastaların 7'si $(\% 23,3)$ evre 1, 4'ü $(\% 13,3)$ evre 2 ve 2'si $(\% 6,6)$ evre 3 idi. Tablo 1'de ROP olan ve olmayan iki grubun karş1laştırmalı olarak hasta özellikleri, retinol-RBP ve plasental retinol geçiş hızı düzeyleri verilmiştir. ROP olan ve olmayanlar arasında retinol ve RBP düzeyleri açısından anlamlı 
fark yoktu. ROP saptanan hastaların plasental retinol geçiş hızı ortanca \%111,5 (62-170), saptanmayanların ortanca \%132 (83-189) idi. ROP olan grupta plasental retinol geçiş hızı ve doğum haftası istatistiksel olarak daha düşük idi (p:0,034, p:0,002). Doğum haftası ile plasental retinol geçiş hızı arasında korelasyon olmamasına rağmen ( $\mathrm{r}: 0.18$, p:0.352), plasental retinol geçiş hızı ile ROP evresi arasın- da negatif korelasyon mevcuttu (r: -0.43, p:0.024).

ROP saptanan hastalardan 4'ünün $(\% 13,3)$ tedavi ihtiyac1 oldu. Zon 2'de evre 3 ROP saptanan 2 hastaya lazer ablasyon, zon 1'de evre 2 ROP ve plus hastalık saptanan 2 hastaya da anti_VEGF uygulandi. Tablo 2'de ROP hastalarının alt grup analizinde umblikal kord-anne retinol, RBP ve

\begin{tabular}{|c|c|c|c|}
\hline & ROP (-) & $\mathrm{ROP}(+)$ & $\mathrm{P}^{*}$ \\
\hline Kord retinol (ng/ml) & $223(176-663)$ & $191(147-332)$ & 0,162 \\
\hline Anne retinol (ng/ml) & $157(123-496)$ & $173(124-301$ & 0,594 \\
\hline Kord RBP $\mathrm{RP}^{* *}(\mathrm{ng} / \mathrm{ml})$ & $7,96(1,53-37,8)$ & $7,3(0,71-13,8)$ & 0,760 \\
\hline Anne $\operatorname{RBP}^{\star *}(\mathrm{ng} / \mathrm{ml})$ & $0,65(0,21-3,44)$ & $0,92(0,16-4,21)$ & 0,321 \\
\hline Plasental retinol geçiş hızı (\%) & $132(83-189)$ & $111,5(62-170)$ & 0,034 \\
\hline Doğum haftası (hafta) & $29(27-30)$ & $28(25-30)$ & 0,002 \\
\hline Doğum ağırlığı (gram) & $1155(760-1490)$ & $1060(570-1300)$ & 0,182 \\
\hline Anne yaşı (yıl) & $27(17-41)$ & $26,5(18-41)$ & 0,660 \\
\hline Erkek/k1z cinsiyet (n) & $11 / 7$ & $6 / 6$ & 0,414 \\
\hline Primipar/multipar (n) & $3 / 15$ & $4 / 8$ & 0,262 \\
\hline Preeklampsi var/yok (n) & $6 / 12$ & $2 / 10$ & 0,278 \\
\hline Antenatal steroid var/yok (n) & $14 / 4$ & $8 / 4$ & 0,391 \\
\hline
\end{tabular}

\begin{tabular}{|c|c|c|c|c|c|}
\hline & ROP (-) & ROP $(+)$ tedavi yok & ROP $(+)$ tedavi var & $\mathrm{P}^{*}$ & $\mathrm{P}^{\star *}$ \\
\hline \multirow{3}{*}{ Kord retinol (ng/ml) } & \multirow{3}{*}{$223(176-663)$} & \multirow{3}{*}{$203(185-332)$} & \multirow{3}{*}{$187(147-191)$} & \multirow{3}{*}{0,098} & (1vs2) 0.522 \\
\hline & & & & & (1vs3)0,064 \\
\hline & & & & & (2vs3) 0,073 \\
\hline \multirow{3}{*}{ Anne retinol (ng/ml) } & \multirow{3}{*}{$157(123-496)$} & \multirow{3}{*}{$181(124-301)$} & \multirow{3}{*}{$167(164-171)$} & \multirow{3}{*}{0,735} & (1vs2)0,689 \\
\hline & & & & & (1vs3)0,681 \\
\hline & & & & & $(2 \mathrm{vs} 3) 0,212$ \\
\hline \multirow{3}{*}{ Kord RBP $P^{* * *}(\mathrm{ng} / \mathrm{ml})$} & \multirow{3}{*}{$7,96(1,53-37,8)$} & \multirow{3}{*}{$7,3(3,36-13,8)$} & \multirow{3}{*}{$4,57(0,71,53)$} & \multirow{3}{*}{0,409} & (1vs2) 0,880 \\
\hline & & & & & (1vs3) 0,383 \\
\hline & & & & & $(2 \mathrm{vs} 3) 0,362$ \\
\hline \multirow{3}{*}{ Anne $\mathrm{RBP}^{* * *}(\mathrm{ng} / \mathrm{ml})$} & \multirow{3}{*}{$0,65(0,21-3,44)$} & \multirow{3}{*}{$0,92(0,45-4,21)$} & \multirow{3}{*}{$0,79(0,16-3,44)$} & \multirow{3}{*}{0,623} & (1vs2) 0,214 \\
\hline & & & & & (1vs3)0,964 \\
\hline & & & & & (2vs3) 0,678 \\
\hline \multirow{3}{*}{$\begin{array}{l}\text { Plasental retinol geçiş } \\
\text { hızı (\%) }\end{array}$} & \multirow{3}{*}{$132(83-189)$} & \multirow{3}{*}{$112(62-170)$} & \multirow{3}{*}{$111(88-114)$} & \multirow{3}{*}{0,040} & (1vs2) 0,230 \\
\hline & & & & & (1vs3)0,016 \\
\hline & & & & & $(2 \mathrm{vs} 3) 0,684$ \\
\hline
\end{tabular}


plasental retinol geçiş hızının ROP olmayanlarla karşılaştırılması verilmiştir. Tedavi ihtiyacı olan ROP hastalarının umblikal kord ve anne retinol, RBP düzeyi ROP olmayanlardan farklı değilken, plasental retinol geçiş hızı ROP saptanmayanlardan anlamlı biçimde daha düşüktü (p:0,016) (Şekil 1). Doğum haftası da tedavi gereksinimi olanlarda ROP olmayanlara göre anlamlı şekilde düşüktü $(\mathrm{p}<0,001)$.

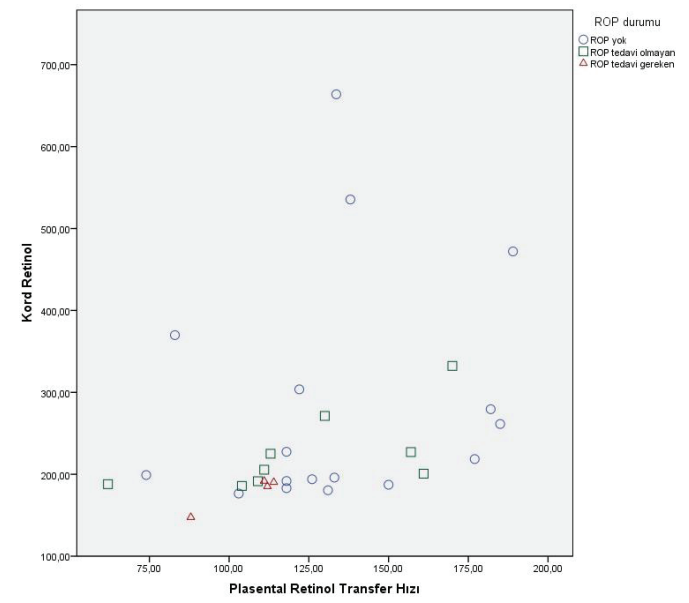

Şekil 1. ROP durumuna göre hastaların umblikal kord retinol ve tranbsplasental retinol geçiş hızı dă̆ılımı.

\section{TARTIŞMA}

Retinolün plasental geçişi oldukça kompleks bir süreç olup henüz anlaşılamamış yönleri vardır., ${ }^{8,9}$ Retinolün hem fazlalığının hem de eksikliğinin teratojenik etkileri olduğu bilinmektedir. Bu nedenle fetusa retinol sağlanmasında plasental homeostazın anahtar rolü bulunmaktadır. ${ }^{7,9}$ Anne retinolü RBP'ye bağlanarak kan-plasenta bariyerine geldikten sonra serbest retinol şeklinde plasentaya geçer., ${ }^{9,12}$ Burada fetusun retinol ihtiyacına göre ya plasental RBP ile dolaşıma salınır ya da retinoidlere dönüşerek plasentada depolanır. ${ }^{9}$ Annenin değişken retinol düzeylerine karşın fetusta daha stabil bir retinol sunumu olmaktadır. ${ }^{8}$ Dolayısıyla ne anne ne de umblikal kord retinol düzeyleri fetusun retinol yararlanımını göstermeye yetmez. Özellikle retinol düzeyinin görece olarak daha düşük olduğu bilinen pretermlerde anne retinolünün ne kadarının plasental RBP ile fetusa sunulabildiği önemlidir. ${ }^{9,13,14} \mathrm{Bu}$ nedenle çalışmamızda retinol ve RBP düzeylerinin yanında plasental retinol transfer hızını da araştırdık. Çalışmamızda tedavi gerektiren ROP hastalarında umblikal kord ve anne retinol düzeylerinin ROP saptanmayanlardan istatiksel olarak farklı olmamasına rağmen, plasental retinol geçişinin anlamlı olarak düşük olması ve plasental retinol transfer hızıyla ROP evresi arasında negatif korelasyon bulunması, plasental retinol homeostazını bozan durumların fetusa retinol sağlanmasında ve ROP gelişiminde etkisi olduğunu düşündürmektedir.

Retinol aynı zamanda bir antioksidandır. ROP gelişiminde oksidatif stresin rolünün olduğu bilinmektedir. ${ }^{3}$ Retinolün VGEF ekspresyonunu azaltarak ROP gelişimini önleyebileceği de rapor edilmiştir. ${ }^{15}$ Pretermlerde doğumda retinol düzeyinin zaten düşük olduğu bilindiğinden literatürde daha çok postnatal vitamin A replasmanının ROP üzerine etkisini araştıran çalışmalar mevcuttur. ${ }^{16,17}$ Ancak çok düşük doğum ağırlıklı pretermlerde umblikal kord retinol düzeyi ile ROP ilişkisini inceleyen çalışmalar da vardır., ${ }^{3,18}$ Özer ve arkadaşları ${ }^{18}$ ROP gelişimi ile retinol düzeyi arasında ilişki olmadığını belirtmiş, ancak antenatal steroid, RBP düzeyi gibi retinol metabolizmasında rol alan etkenlerin kendi çalışmalarında değerlendirilmediğinden bahsetmişlerdir. Çalışmamızda umblikal kord ve annenin hem retinol hem de RBP düzeylerinin ROP gelişimi üzerine etkisinin olmadığını saptadık. Bilebildiğimiz kadarıyla umblikal kord ve anne RBP ile ROP ilişkisini inceleyen başka çalışma yoktur.

Antenatal steroidin umblikal kord retinol düzeyi üzerine etkisine dair farklı sonuçlar bildirilmiştir. ${ }^{19,20}$ Inder ve arkadaşlarının ${ }^{19}$ retinol ile solunum morbiditesi ilişkisini inceledikleri çalışmasında antenatal steroid uygulamasının umblikal kord retinol düzeyini artırdığı rapor edilmiştir. Chen ve arkadaşlari ${ }^{20}<29$ hafta ve/veya $<1250$ gr bebeklerde antenatal steroid uygulamasının doğumdan sonra ilk 48 saat içerisinde bakılan serum retinol düzeyi eksiklik $(<20 \mu \mathrm{g} / \mathrm{dl})$ sıklığını değiştirmediğini bildirmiştir. Çalışmamıda steroid uygulanma durumu ile retinol düzeyleri arasında ilişki yoktu. Bunun yanında steroid uygulanma 
durumunun ROP sıklığını ve plasental retinol geçiş hızını da değiştirmediği saptandı.

Doğum haftası ve ağırlığı azaldıkça ROP görülme sıklığ1nın arttığı bilinmektedir. 1 Çalışmamızda doğum haftası ile ROP görülme sıklığı arasında ilişki saptandı. Ancak doğum ağırlığının çalışma grubumuzda farklı olmadığını gördük. Zaten çok düşük doğum ağırlıklı ve <30 hafta bebeklerin çalışmaya dahil edilmesi doğum ağırlığının homojen dağılmasına neden olmuş olabilir.

\section{Çalışma kısıtlılıkları}

Hasta alım periyodunda ROP takibi yapilabilen hasta sayısının düşük olması dolayısıyla tedavi gereken hastaların sayısının düşüklüğüne neden olmuştur. Bu nedenle istatistik olarak daha güvenilir sonuçlar elde edilememiş olabilir. Retinol transfer hızı üzerine etkili olabilecek plasental fonksiyonların doppler ultrasonografi gibi yöntemlerle değerlendirilmemesi çalışmamızın bir diğer kısıtlılı̆̆ıdır.

\section{SONUÇ}

Sonuç olarak preterm bebeklerde intrauterin dönemde ne anne ne de umblikal kord retinol eksikliğinin tedavi gerektiren ROP ile ilişkisi yoktur. Ancak plasental retinol geçiş hızı ile tedavi gerektiren ROP arasında ilişkili saptanmıştır. Bu nedenle ciddi ROP gelişimini öngörmede plasental retinol geçiş hızına bakılmasının faydalı olabileceği kanaatindeyiz. Bu konuda daha geniş katılımlı ve plasental retinol homeostazını inceleyen çalışmalara ihtiyaç vardır.

\section{Etik Kurul Onayı}

Çalışma için Atatürk Üniversitesi Tıp Fakültesi Etik Kurulu'ndan onay alındı (Onay no: Tarih: 26.06.2020 20207/29).

\section{Çıkar Çatışması}

Yazarlar tarafından çıkar çatışması bildirilmemiştir.

\section{Katkı Oranı Beyanı}

Dizayn: K.Ş.T. Medikal Uygulama: K.Ş.T., M.K., D.K., M.Y. Konsept: K.Ş.T, D.K. Veri Toplama veya İşleme: K.Ş.T, D.K.. Analiz veya Yorumlama: K.Ş.T. , S.E.T. Literatür Arama: K.Ş.T, D.K, S.E.T. Yazan: K.Ş.T 
Sakarya Tip Dergisi 2021;11(3):654-660

TEKGÜNDÜZ ve Ark., Prematüre Retinopatisinde Retinol Metabolizma Değişkenleri

\section{Kaynaklar}

1. Bas AY, Demirel N, Koc E, Ulubas Isik D, Hirfanoglu IM, Tunc T; TR-ROP Study Group. Incidence, risk factors and severity of retinopathy of prematurity in Turkey (TR-ROP study): a prospective, multicentre study in 69 neonatal intensive care units. Br J Ophthalmol 2018; 102 (12):1711-1716. doi: 10.1136/bjophthalmol-2017-311789.

2. Sun Y, Hellström A, Smith Lois EH. Retinopathy of prematurity. In: Martin RJ, Fanaroff AA, Walsh MC, (eds). Fanaroff and Martin's neonatal perinatal medicine- diseases of the fetus and newborn. Philadelphia: Elsevier; 2015;.p.1767-74.

3. Agrawal G, Dutta S, Prasad R, Dogra MR. Fetal oxidative stress, micronutrient deficien$c y$ and risk of retinopathy of prematurity: a nested case-control study. Eur J Pediatr 2021 80(5):1487-1496. doi: 10.1007/s00431-020-03896-x.

4. Section on Ophthalmology, American Academy of Pediatrics; American Academy of Ophthalmology; American Association for Pediatric Ophthalmology and Strabismus. Screening examination of premature infants for retinopathy of prematurity. Pediatrics 2013; 131: 189-95.

5. Morriss-Kay GM, Ward SJ. Retinoids and mammalian development. Int Rev Cytol 1999; 188:73-131. doi:10.1016/s0074-7696(08)61566-1.

6. Zhang BY, Zhang T, Lin LM, Wang F, Xin RL, Gu X, et al. Correlation between birth defects and dietary nutrition status in a high incidence area of China. Biomed Environ Sci 2008; 21(1):37-44. doi: 10.1016/S0895-3988(08)60005

7. Lammer EJ, Chen DT, Hoar RM, Agnish ND, Benke PJ, Braun JT, Curry CJ, Fernhoff PM, Grix AW Jr, Lott IT, et al. Retinoic acid embryopathy. N Engl J Med 1985; 3;313(14):837-41. doi: 10.1056/NEJM198510033131401.

8. Bastos Maia S, Rolland Souza AS, Costa Caminha MF, Lins da Silva S, Callou Cruz RSBL, Carvalho Dos Santos C, et al. Vitamin A and Pregnancy: A Narrative Review. Nutrients 2019: 22;11(3):681. doi: 10.3390/nu11030681.

9. Marceau $G$, Gallot D, Lemery D, Sapin V. Metabolism of retinol during mammalian placental and embryonic development. Vitam Horm 2007: 75:97-115. doi: 10.1016/S00836729(06)75004-X.

10. Koç E, Baş AY, Özdek Ş, Ovalı F, Başmak H. Turkish Neonatal and Turkish Ophthalmology Societies consensus guideline on the retinopathy of prematurity. Turk Pediatri Ars 2018; 25;53(Suppl 1):S151-S160. doi: 10.5152/Turk Pediatr iArs.2018.01815.
11. Thoene M, Haskett H, Furtado J, Thompson M, Van Ormer M, Hanson C, et al. Effect of Maternal Retinol Status at Time of Term Delivery on Retinol Placental Concentration, Intrauterine Transfer Rate, and Newborn Retinol Status. Biomedicines 2020: 8(9):321. doi:10.3390/biomedicines8090321.

12. Quadro L, Hamberger L, Gottesman ME, Colantuoni V, Ramakrishnan R, Blaner WS. Transplacental delivery of retinoid: the role of retinol-binding protein and lipoprotein retinyl ester. Am J Physiol Endocrinol Metab 2004: 286(5):E844-51. doi: 10.1152/ajpendo.00556.2003.

13. Brandt RB, Mueller DG, Schroeder JR, Guyer KE, Kirkpatrick BV, Hutcher NE et. Serum vitamin A in premature and term neonates. J Pediatr 1978: 92:101e4. doi: 10.1016/s00223476(78)80086-9.

14. Mactier H. Vitamin A for preterm infants; where are we now? Semin Fetal Neonatal Med 2013 ;18(3):166-171. doi: 10.1016/j.siny.2013.01.004.

15. Pal S, Iruela-Arispe ML, Harvey VS, et al. Retinoic acid selectively inhibits the vascular permeabilizing effect of VPF/VEGF, an early step in the angiogenic cascade. Microvasc Res 2000; 60:112-20.

16. Darlow BA, Graham PJ, Rojas-Reyes MX. Vitamin A supplementation to prevent mortality and short-and long-term morbidity in very low birth weight infants. Cochrane Database Syst Rev 2016: 22;2016(8):CD000501. doi: 10.1002/14651858.CD000501

17. Sun H, Cheng R, Wang Z. Early Vitamin A Supplementation Improves The Outcome Of Retinopathy Of Prematurity In Extremely Preterm Infants. Retina 2020; 40(6):1176-1184. doi:10.1097/IAE.0000000000002543.

18. Arun Özer E, Sivaslı Gül Ö, Men G, Talay E, Sütçüoğlu S, Kanık A, Türkoğlu E, Kahramaner Z, Coșar H, Erdemir A, Yaprak I. Retinopathy of Prematurity in Very Low Birth Weight Infants: Effects of Serum Vitamin A and Clinical Parameters. Turk J Ophthalmol 2011; 41:309-313.

19. Inder TE, Graham PJ, Winterbourn CC, Austin NC, Darlow BA. Plasma vitamin A levels in the very low birthweight infant e relationship to respiratory outcome. Early Hum Dev 1998; 52:155e68. https://doi.org/ 10.1016/s0378-3782(98)00026-7

20. Chen HJ, Hsu CH, Chiang BL. Serum retinol levels and neonatal outcomes in preterm infants. J Formos Med Assoc 2017: 116(8):626-633. doi: 10.1016/j.jfma.2017.04.019. 